\title{
BMJ Open Goal-directed perfusion to reduce acute kidney injury after paediatric cardiac surgery (GDP-AKIp): study protocol for a prospective randomised controlled trial
}

Yan Zhang (D) , Xiujuan Zhou, Bo Wang, Lijuan Guo, Ronghua Zhou

To cite: Zhang Y, Zhou X, Wang B, et al. Goal-directed perfusion to reduce acute kidney injury after paediatric cardiac surgery (GDPAKIp): study protocol for a prospective randomised controlled trial. BMJ Open 2020;10:e039385. doi:10.1136/ bmjopen-2020-039385

- Prepublication history and additional material for this paper are available online. To view these files, please visit the journal online (http://dx.doi. org/10.1136/bmjopen-2020039385).

$\mathrm{YZ}$ and $\mathrm{XZ}$ contributed equally.

YZ and XZ are joint first authors.

Received 14 April 2020

Revised 27 0ctober 2020 Accepted 29 0ctober 2020

\section{Check for updates}

(C) Author(s) (or their employer(s)) 2020. Re-use permitted under CC BY-NC. No commercial re-use. See rights and permissions. Published by BMJ.

Anesthesiology, West China Hospital of Sichuan University, Chengdu, China

Correspondence to

Dr Ronghua Zhou;

wr.zhou@hotmail.com

\section{ABSTRACT}

Introduction Cardiac surgery-associated acute kidney injury (CS-AKI) occurs in up to $40 \% \sim 60 \%$ of paediatric patients and increases postoperative morbidity and mortality. A goal-directed perfusion (GDP) strategy aimed at maintaining indexed oxygen delivery $\left(\mathrm{DO}_{2} \mathrm{i}\right)$ above the critical threshold (reported to be $260 \sim 300 \mathrm{~mL} / \mathrm{min} /$ $\mathrm{m}^{2}$ in adults) during cardiopulmonary bypass (CPB), is effective in reducing the incidence of CS-AKI. However, no clear standards of paediatric critical $\mathrm{DO}_{2} \mathrm{i}$ exist. Our prior prospective cohort study exploring the critical $\mathrm{DO}_{2} \mathrm{i}$ threshold during paediatric $\mathrm{CPB}$ has found the nadir $\mathrm{DO}_{2} \mathrm{i}$ $<353 \mathrm{~mL} / \mathrm{min} / \mathrm{m}^{2}$ was an independent risk predictor of CS-AKI. Based on this background, this trial is designed to further determine whether the implementation of the GDP initiative aimed at maintaining $\mathrm{DO}_{2} \mathrm{i} \geq 360 \mathrm{~mL} / \mathrm{min} /$ $\mathrm{m}^{2}$ would reduce the rate of CS-AKI in paediatrics and improve clinical outcome.

Methods and analysis This is a prospective, singlecentre, randomised controlled trial. In total, 166 paediatric patients undergoing cardiac surgery will be randomly allocated to the GDP group or control group. Patients in the GDP arm will be treated with a GDP strategy during $\mathrm{CPB}$ aimed to maintain $\mathrm{DO}_{2} \mathrm{i}$ at $\geq 360 \mathrm{~mL} / \mathrm{min} / \mathrm{m}^{2}$ (to ensure safely above the risk $\mathrm{DO}_{2} \mathrm{i}$ threshold we found). The perfusion strategy for patients in the control arm will be factored on body surface area and temperature. The primary outcome is the rate of postoperative CS-AKI (it is defined according to paediatric Risk, Injury, Failure, Loss of renal function and End-stage renal disease criteria). The secondary end points include: (1) the other oxygen metabolism parameters during CPB; (2) major complication and all-cause mortality (in-hospital or within 30 days postoperatively); (3) short-term clinical outcomes (ie, time to extubation, mechanical ventilation time, hospital stay).

Ethics and dissemination The study has been approved by the Biomedical Research Ethics committee of West China Hospital of Sichuan University (approval number: 2019(863)). Results will be disseminated through peerreviewed publications and conferences. Trial registration number ChiCTR2000029232.
Strengths and limitations of this study

- This will be the first randomised controlled trial to explore the clinical effects of goal-directed perfusion (GDP) for postoperative cardiac surgery-associated acute kidney injury (CS-AKI) in paediatrics.

- This perfusion strategy is specifically tailored to the infants.

- We choose the target of $360 \mathrm{~mL} / \mathrm{min} / \mathrm{m}^{2}$ as the indexed oxygen delivery $\left(\mathrm{DO}_{2} \mathrm{i}\right)$ threshold which is safely above the critical $\mathrm{DO}_{2} \mathrm{i}$ obtained from our prior prospective cohort study.

- A limitation of the study is the lack of a precise and quantifiable measures of diagnosing early CS-AKI.

\section{INTRODUCTION}

Infants or children undergoing open cardiac surgery are at high risk of developing cardiac surgery-associated acute kidney injury (CSAKI), with the incidence of $40 \%-60 \% .{ }^{1-3}$ Paediatric CS-AKI increases postoperative morbidity and mortality, which also adversely affects the long-term prognosis. CS-AKI has a complex pathophysiology with many risk factors, ${ }^{45}$ and therefore no single medication or therapy has been demonstrated to be effective for treatment or prevention. ${ }^{6} 7$ However, it has been established that the associated low oxygen delivery is one of the important predicators of CS-AKI. ${ }^{8-10}$ Therefore, in the absence of an intervention to prevent CS-AKI, a reasonable strategy to identify modifiable risk factors and to meet physical oxygen demand may reduce the risk of CS-AKI.

Oxygen delivery $\left(\mathrm{DO}_{2}\right)$ during $\mathrm{CPB}$ is calculated by multiplying the pump flow rate and the arterial oxygen content, which is more comprehensive in reflecting tissue oxygen supply than the independent parameters of arterial oxygen saturation $\left(\mathrm{SaO}_{2}\right)$, cardiac output and haemoglobin concentration. ${ }^{11}$ 
So, indexed $\mathrm{DO}_{2}\left(\mathrm{DO}_{2} \mathrm{i}\right)$ is one of the most important determinants of 'optimal perfusion' during CPB. ${ }^{11}$ The minimal safe $\mathrm{DO}_{2} \mathrm{i}$ during $\mathrm{CPB}$, termed 'critical $\mathrm{DO}_{2} \mathrm{i}$ ', is the point when the maximal oxygen extraction is reached, and the whole body oxygen consumption $\left(\mathrm{VO}_{2}\right)$ and tissue oxygenation begin to decrease, and anaerobic metabolism and lactic acidosis begin to develop. ${ }^{11}$ In recent years, the concept of goal-directed perfusion (GDP) aimed at maintaining the nadir $\mathrm{DO}_{2} \mathrm{i}$ on $\mathrm{CPB}$ above the critical value has been proved to be effective to reduce the incidence of CS-AKI. ${ }^{8-10}$ Therefore, nadir $\mathrm{DO}_{2} \mathrm{i}$ is a stronger predictor of CS-AKI than nadir haemoglobin or perfusion flow rate alone. ${ }^{12}$

Several clinical studies have explored the "critical $\mathrm{DO}_{2} \mathrm{i}^{\prime}$ threshold in adult cardiac surgeries. Ranucci $e t$ $a l^{13}{ }^{2}$ reported that $\mathrm{DO}_{2}$ i value $<260 \mathrm{~mL} / \mathrm{min} / \mathrm{m}^{2}$ was associated with increased lactate formation. Subsequently, numerous retrospective and prospective observational studies have confirmed the association between nadir $\mathrm{DO}_{2} \mathrm{i}$ on $\mathrm{CPB}$ and postoperative AKI, with the identification of a 'critical $\mathrm{DO}_{2} \mathrm{i}$ ' in the range of $262-272 \mathrm{~mL} /$ $\mathrm{min} / \mathrm{m}^{2}$ for adult patients undergoing $\mathrm{CPB} .^{8-10}$ In 2018 , a multicentre randomised controlled trial (RCT) showed that a GDP strategy, with maintenance of $\mathrm{DO}_{2} \mathrm{i}>280 \mathrm{~mL} /$ $\min / \mathrm{m}^{2}$, was effective in reducing Acute Kidney Injury Network (AKIN) stage 1 postoperative AKI. ${ }^{14}$ Moreover, in 2019, Mukaida et $a l^{15}$ has tested that the time-dose response of $\mathrm{DO}_{2} \mathrm{i}$ during $\mathrm{CPB}$ was a better indicator than nadir $\mathrm{DO}_{2} \mathrm{i}$ in evaluating $\mathrm{AKI}$ risk, and maintaining $\mathrm{DO}_{2} \mathrm{i}$ level $>300 \mathrm{~mL} / \mathrm{min} / \mathrm{m}^{2}$ may result in decreased risk for postoperative AKI. However, all the studies about the critical $\mathrm{DO}_{2} \mathrm{i}$ thresholds on $\mathrm{CPB}$ and the relationship between the nadir $\mathrm{DO}_{2} \mathrm{i}$ and CS-AKI are all limited to the adult population. The literature in paediatric patients is scarce and no evidence-based paediatric critical $\mathrm{DO}_{2} \mathrm{i}$ threshold is universally accepted. Given that infants have a much higher metabolic rate and oxygen demand, consequently they require a much higher pump flow rate $(3.2 \mathrm{~L} / \mathrm{min}$ / $\mathrm{m}^{2}$ body surface area (BSA) vs $2.4 \mathrm{~L} / \mathrm{min} / \mathrm{m}^{2} \mathrm{BSA}$ ) and haematocrit (HCT) than adults. So, the critical $\mathrm{DO}_{2} \mathrm{i}$ in infants cannot be referred to the existing adults' standard, otherwise it will cause severe hypoperfusion and hypoxia.

Therefore, our research group has innovatively conducted a pilot prospective cohort study to explore the critical $\mathrm{DO}_{2} \mathrm{i}$ threshold in paediatric cardiac patients, with the association of postoperative AKI (trial registration number: ChiCTR1900028683). The results showed that nadir $\mathrm{DO}_{2} \mathrm{i}$ was significantly different between the non-AKI and AKI groups. And the nadir $\mathrm{DO}_{2} \mathrm{i}$ on $\mathrm{CPB}$ less than the critical value threshold of $353 \mathrm{~mL} / \mathrm{min} / \mathrm{m}^{2}$ was an independent risk predictor of CS-AKI in infants. However, further studies are needed to define the effects of GDP approach in paediatrics.

Based on this background, the current RCT of GDP strategy to reduce AKI after paediatric cardiac surgery (GDP-AKIp) is designed to further study whether the GDP approach aimed at avoiding the nadir $\mathrm{DO}_{2} \mathrm{i}$ less than the critical threshold of $360 \mathrm{~mL} / \mathrm{min} / \mathrm{m}^{2}$ will reduce the rate of postoperative AKI in paediatric patients undergoing mild hypothermic $\mathrm{CPB}$, and improve the clinical outcome.

\section{OBJECTIVE}

To demonstrate that the implementation of the GDP initiative aimed at maintaining $\mathrm{DO}_{2} \mathrm{i} \geq 360 \mathrm{~mL} / \mathrm{min} /$ $\mathrm{m}^{2}$ compared with standard CPB flow rate management factored on BSA and temperature would reduce the rate of CS-AKI in paediatrics and improve clinical outcome, we will test the following hypothesis:

- The implementation of the GDP initiative would be associated with a reduced AKI incidence within 7 days of paediatric cardiac surgery compared with control patients.

\section{METHODS/DESIGN \\ Study design}

The GDP-AKIp study is a single-centre, prospective, double-blinded, two-armed, RCT with a 1:1 allocation ratio, testing whether the GDP strategy will reduce the rate of CS-AKI and improve clinical outcome in paediatric patients. The protocol structure is written according to the Consolidated Standards of Reporting Trials 2010 Statement guidelines and follows the Standard Protocol Items: Recommendations for Interventional Trials (SPIRIT) Statement. The SPIRIT checklist can be found in online supplemental additional file 1 . Figure 1 is the trial flow chart. The schedule of enrolment, interventions and assessments follows the SPIRIT Statement (figure 2).

This trial will be undertaken in West China Hospital of Sichuan University, where $>300$ infant open-heart procedures with $\mathrm{CPB}$ are performed each year. Recruitment will be commenced in April 2020.

\section{Participants}

We plan to enrol 166 paediatric participants aged $<3$ years undergoing CPB for any elective cardiac surgical procedure via a median sternotomy.

\section{Inclusion criteria}

Participants must meet all the inclusion criteria:

1 . aged $\leq 3$ years;

2. undergoing elective cardiac surgery via a median sternotomy under CPB;

3. American Society of Anesthesiologists I-IV level;

4. there is a written informed consent.

\section{Exclusion criteria}

Patients who meet any of the following criteria will be excluded from participation:

1. chronic kidney disease stage 5 (receipt of kidney replacement therapy or estimated glomerular filtration rate $\left.(\mathrm{eGFR})<15 \mathrm{~mL} / \mathrm{min} / 1.73 \mathrm{~m}^{2}\right)^{16}$;

2. expected nadir $\mathrm{CPB}$ temperature $<32^{\circ} \mathrm{C}$;

3. heart transplantation;

4. suffering perioperative cardiac arrest; 


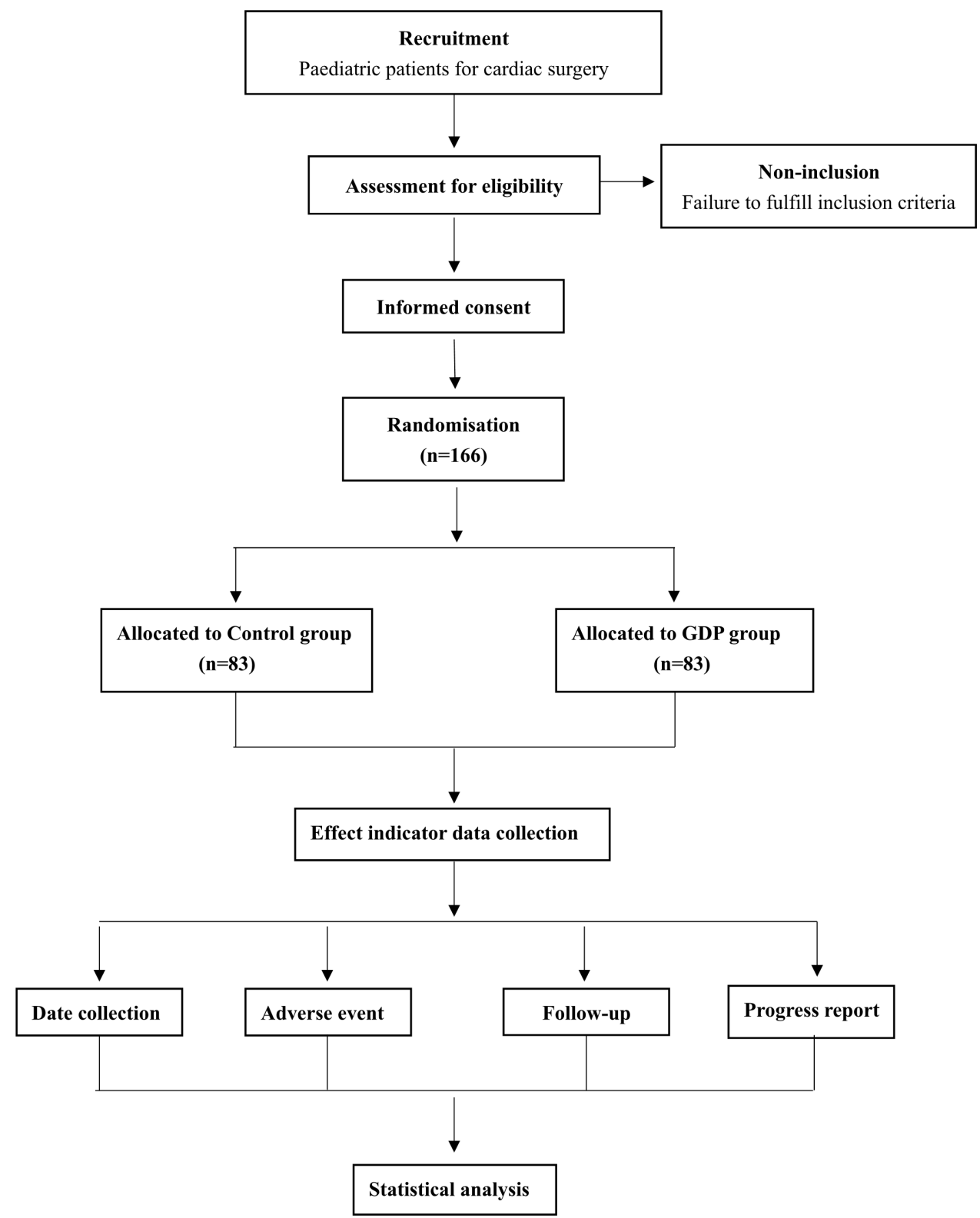

Figure 1 Flow chart. GDP, goal-directed perfusion.

5. aortic arch and other deep hypothermic circulatory arrest surgery;

6. preoperative treatment with extracorporeal life support;

7. postoperative treatment with extracorporeal life support or ventricular auxiliary device (VAD);

8. participating in other interventional studies;

9. premature infants and those with pre-existing brain or kidney abnormalities.

\section{Randomisation/Blinding}

Once informed consent has been received and the preoperative assessments completed, patients will be enrolled into the trial. In this study, a statistician in the study will use the IBM SPSS Statistics V.19.0 software to generate a table of random numbers. The ratio of test-to-control is 1:1 and the block size is 2. Patients will be randomly assigned to either GDP or control arms according to enrolment sequence. A table of random numbers will be placed in sequentially labelled opaque envelopes. The distribution order will be kept by a research assistant who is not involved in recruitment, intervention, outcome evaluation or statistical analysis. After the subjects have met the study criteria, the research assistant will notify the appropriate perfusionist to intervene by telephone of the assignment (GDP group or control group).

The perfusionists will be aware of patients' group allocation because they will provide the trial intervention, but they will not be involved in either the postoperative treatment or the analysis. The patients, the surgeons, the anaesthesiologists, the paediatric intensive care unit (PICU) physicians, the data collectors and the data analysts are blinded to treatment allocation in the whole process. To ensure these people are blinded to the perfusion strategy, 


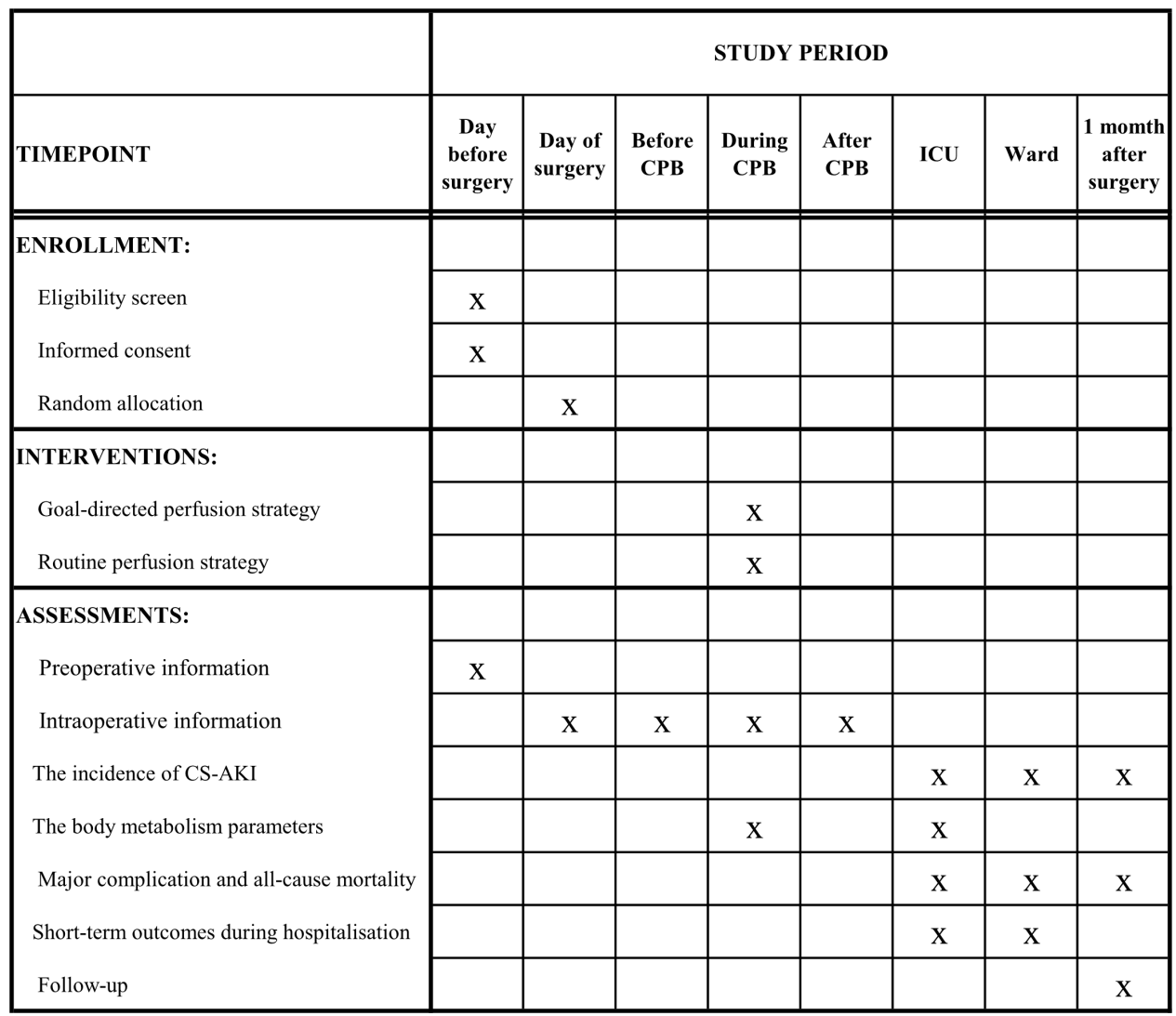

Figure 2 Schedule of enrolment, interventions, assessments according to Standard Protocol Items: Recommendations for International Trials (SPIRIT). CPB, cardiopulmonary bypass; CS-AKI, cardiac surgery-associated acute kidney injury; ICU, intensive care unit.

the patient files typically the perfusion records will not be involved information related to the study arm.

\section{Interventions}

Patients who meet the enrolment criteria will be randomised 1:1 to either control or GDP group.

Patients in the control group will receive arterial pump flow based on BSA and temperature, with a target value of $2.8 \sim 3.2 \mathrm{~L} / \mathrm{min} / \mathrm{m}^{2}$. Ultrafiltration and transfusion of packed red blood cell (PRBC) during CPB will be triggered by the HCT value, according to local institutional standards.

Patients in the GDP group will receive a GDP strategy during CPB aimed to maintain $\mathrm{DO}_{2} \mathrm{i}$ at $\geq 360 \mathrm{~mL} / \mathrm{min}$ / $\mathrm{m}^{2}$. The main intervention will be based on adjustment of the arterial pump flow according to the HCT value so as to reach and maintain a $\mathrm{DO}_{2} \mathrm{i}$ above the prespecified threshold. In the event of low HCT values and an inability to maintain the $\mathrm{DO}_{2} \mathrm{i}$ above the threshold, transfusing PRBC or ultrafiltration could be considered.

With respect to the other perfusion details, the patients will be treated according to our hospital standards. The $\mathrm{DO}_{2} \mathrm{i}$ levels of patients in both study arms during CPB are reported at $10 \mathrm{~min}$ intervals. For patients in the GDP group, the perfusionist will have a direct view of the GDP monitor data to achieve compliance with the GDP protocol. For patients in the control group, the $\mathrm{DO}_{2} \mathrm{i}$ value will be excluded from the record form to avoid any intervention based on values in the control group.

\section{Study end points}

The primary end point is the rate of AKI after cardiac surgery. AKI is defined according to paediatric Risk, Injury, Failure, Loss of renal function and End-stage renal disease (pRIFLE) classification at the risk or greater level as any increase in estimated creatinine clearance $(\mathrm{eCrCl})>25 \%$ from baseline (obtained within 1 week before surgery) to peak value within the first 7 days postsurgery. ${ }^{17}$ Moreover, to accurately reflect changing renal function, adjusting serum creatinine ( $\mathrm{SCr}$ ) values for fluid balance will be used. Adjusted $\mathrm{SCr}=$ measured $\mathrm{SCr} \times(1+$ [cumulative net fluid balance (L)/total body water $(\mathrm{kg}) \mathrm{]})$. Postoperative $\mathrm{SCr}$ will be recorded daily for 7 days. We will also record peak SCr during hospital stay and SCr before discharge on all patients. We will calculate pRIFLE scores using the eGFR calculated from the eCrCl with the Schwartz formula ${ }^{18}$ : eGFR $\left(\mathrm{mL} / \mathrm{min}\right.$ per $\left.1.73 \mathrm{~m}^{2}\right)=0.413 \times$ height $(\mathrm{cm}) / \mathrm{SCr}(\mathrm{mg} / \mathrm{dL})$. Our AKI definition will not include urine output as urine output is frequently influenced by modified ultrafiltration and diuretic use.

The secondary end points include: (1) the other oxygen metabolism parameters during $\mathrm{CPB}$, including mixed venous oxygen saturation $\left(\mathrm{SvO}_{2}\right)$, the peak lactate concentration and regional cerebral and renal oxygen 
saturation, (2) major complication (ie, low cardiac output syndrome; typically based on two or more of the following: cardiac index $\leq 2.2 \mathrm{~L} / \mathrm{min} / \mathrm{m}^{2}$, blood lactate $>3 \mathrm{mmol} / \mathrm{L}$ or increase in blood lactate of at least 2 $\mathrm{mmol} / \mathrm{L}$ from baseline, $\mathrm{SvO}_{2}<50 \%$ or increase in $\mathrm{SaO}_{2}$ to $\mathrm{SvO}_{2}$ difference by at least $20 \%$ from baseline, urine output $<1 \mathrm{~mL} / \mathrm{kg}$ /hour, peripheral skin temperature to core body temperature difference of $>7^{\circ} \mathrm{C}$ ), ${ }^{19}$ severe respiratory failure based on blood gas, treatment for pneumonia (ie, antibiotics), sepsis, deep sternal wound infection and all-cause mortality (in-hospital or in-hospital or within 30 days postoperatively), (3) short-term clinical outcomes including time to extubation, mechanical ventilation time, PICU time, length of hospital stay.

\section{Perioperative management and monitoring}

General anaesthesia will be induced with midazolam, sufentanil and propofol as necessary. Tracheal intubation will be facilitated with either rocuronium or cisatracurium. There is no restriction on the type or dose of anaesthetic used to induce anaesthesia. The trachea will be intubated, and mechanical ventilation starts to achieve an end-tidal carbon dioxide tension of $35 \sim 45 \mathrm{~mm} \mathrm{Hg}$. After the induction, anaesthesia will be maintained with continuous infusion of propofol or inhalation of sevoflurane until the end of surgery. Midazolam, sufentanil and cisatracurium will be given as needed.

A standard CPB equipment with a disposable hollowfibre membrane oxygenator (Pixie, Medtronic, USA) and a roller pump (Stockert-5, Sorin Group, Germany) will be selected. The pump circuit will be primed with 150 200 mL acetated Ringer's solution, 1-2 units PRBC, $10 \mathrm{~g}$ albumin, $1.25 \mathrm{~mL} / \mathrm{kg} 20 \%$ mannitol and $10-20 \mathrm{~mL}$ $5 \%$ sodium bicarbonate. Cold modified St. Thomas blood cardioplegia (1:4) at the dose of $30 \mathrm{~mL} / \mathrm{kg}$ will be used for all patients. The cardioplegia will be repeated half dose every 20 25 min during surgery. Pump flow rate will be targeted between 2.8 and $3.2 \mathrm{~L} / \mathrm{min} / \mathrm{m}^{2}$. Surgery will be performed under mild hypothermia $\left(33^{\circ} \mathrm{C}-34^{\circ} \mathrm{C}\right)$, with mean arterial pressure 30 45 $\mathrm{mm} \mathrm{Hg}$ and HCT 25\% 30\% during CPB. Blood gases and haemoglobin values will be measured at the following detailed time points. After the cardiac surgical procedure and aortic unclamping, the heart will be defibrillated if sinus rhythm does not resume spontaneously. And after weaning from CPB, modified ultrafiltration (MUF) will be routinely performed and the HCT will be maintained at 30\% 35\%. Then, protamine will be used to reverse the effect of heparin. Postoperatively, all patients will be transferred to the PICU.

The blood gases will be routinely monitored at the following time points, that is, after anaesthesia induction, CPB initiation, 5 min after aortic clamping, every 10 min during the periods of aortic cross-clamping, at rewarming, before CPB weaning and after MUF. Moreover, during CPB, blood gases should be re-examined 5 min after the completion of any intervention measures, such as adjustment of pump flow rate and ventilation parameters, blood transfusion, ultrafiltration and so on.
The $\mathrm{DO}_{2} \mathrm{i}$ will be calculated based on the blood gases during the period of aortic cross-clamping. The nadir $\mathrm{DO}_{2} \mathrm{i}$ will be taken as the lowest of all calculated values. And the $\mathrm{DO}_{9} \mathrm{i}$ will be computed using the following formula ${ }^{13}: \quad \mathrm{DO}_{2} \mathrm{i} \quad\left(\mathrm{mL} / \mathrm{min} / \mathrm{m}^{2}\right)=$ pumpflow $\quad(\mathrm{L} / \mathrm{min} /$ $\left.\mathrm{m}^{2}\right) \times(1.36 \times$ haemoglobin $(\mathrm{g} / \mathrm{L}) \times$ haemoglobin saturation $(\%)+0.031 \times$ partial pressure of arterial oxygen $(\mathrm{mm}$ $\mathrm{Hg})) / \mathrm{BSA}\left(\mathrm{m}^{2}\right)$.

$\mathrm{SvO}_{2}$ and lactate concentration should also be recorded every $10 \mathrm{~min}$ from blood gas during CPB. Renal and cerebral regional oxygen saturation $\left(\mathrm{rSO}_{2}\right)$ will be continuously measured every $2 \mathrm{~s}$ (EGOS-600A) from the time of anaesthesia to the time of transfer from the operating room to PICU. Baseline $\mathrm{rSO}_{2}$ levels (before CPB) and both average and nadir levels for the intraoperative period will be recorded. We will also evaluate cumulative time spent during $\mathrm{CPB}$ at or below a $\mathrm{rSO}_{2}$ value $20 \%$ less than baseline and cumulative time spent at or above a $\mathrm{rSO}_{2}$ value $20 \%$ more than baseline.

\section{Data collection}

All the related data will be collected on the case report form. Preoperative data include patient demographics (sex, age, weight, presence of cyanotic lesions and Fontan candidates), preoperative cardiovascular profile (ejection fraction, New York Heart Association functional class, Society of Thoracic Surgeons-European Association for cardiothoracic surgery congenital heart surgery mortality score (STAT) score,${ }^{20}$ pulmonary hypertension and the use of ACE inhibitor, diuretics and $\beta$-blockers prior to cardiac surgery), presence of comorbidities (lung infection, hypothyroidism, previous cerebrovascular accident) and laboratory assays (SCr value and haemoglobin). Operative data including type of operation, CPB duration, aortic cross-clamp time, nadir body temperature during $\mathrm{CPB}$, number of PRBC units transfused during surgery, $\mathrm{rSO}_{2}$ value, nadir $\mathrm{SvO}_{2}$, nadir $\mathrm{DO}_{2} \mathrm{i}$ and the peak blood glucose and lactate concentration on CPB will be assessed. We will record postoperative data including SCr value, AKI stage, the peak lactate and blood glucose concentration in the PICU, the number of PRBC units transfused in the PICU, the maximum VIS score, urine output (mL/kg/hour), maximum fluid overload (FO) (ie, (daily (fluid in (L)-fluid out (L) $) \times 100 /$ PICU admission patient weight $(\mathrm{kg})$ ) within the first week of PICU admission and cumulative $\mathrm{FO}(\mathrm{cFO})(\mathrm{eg}, \mathrm{cFO}=\% \mathrm{FO}$ day of surgery $(\mathrm{DOS})+\% \mathrm{FO}$ postoperative day 1 ; also, for DOS, the cFO includes intraoperative fluid status. ${ }^{21} \mathrm{We}$ will also evaluate the association between CS-AKI and postoperative short-term outcomes (major complication and all-cause mortality, time to extubation, mechanical ventilation time, PICU time, hospital stay).

\section{Statistical considerations}

Sample size estimate

The sample selected for this study is based on the finding of our prior pilot cohort study exploring the critical $\mathrm{DO}_{2} \mathrm{i}$ threshold in paediatric patients undergoing cardiac 
surgery with CPB. That study showed that $38.5 \%$ paediatric patients developed CS-AKI postoperatively. A noninferiority threshold of $10 \%$ is considered according to previous studies. ${ }^{14}$ A sample size of 75 per group will yield $80 \%$ power to obtain a significant difference between the two groups, using a two-sample t-test at a one-sided 0.025 level of significance. To account for an approximately $10 \%$ dropout rate, a total of 166 subjects (83 subjects for each group) will be enrolled.

\section{Statistical analyses}

Continuous variables will be described as the mean (SD), median (IQR) when not normally distributed and categorical variables with count $(\mathrm{n})$ and proportions (\%). The normality of distribution will be tested with the Kolmogorov-Smirnov test. Baseline characteristics will be compared using $\chi^{2}$ or Fisher's exact tests and a Student's t-test. The primary outcome, the occurrence of AKI after surgery, will be compared using $\chi^{2}$ or Fisher's exact tests, and the relative risks and the $95 \%$ CI will be calculated. The secondary outcomes, which are the continuous variables, will be performed using unequalvariance Student's t-test. The other secondary outcomes, including the major complication and all-cause mortality will be compared using $\chi^{2}$ or Fisher's exact tests. In addition, a multiple logistic regression analysis will be used to identify relevant covariates (the oxygen metabolism parameters such as $\mathrm{DO}_{2} \mathrm{i}, \mathrm{SvO}_{2}$, lactate, $\mathrm{rSO}_{2}$ value and other risk factors such as $\mathrm{CPB}$ duration, age, $\% \mathrm{FO}$ ) associated with the primary outcome. Analyses of morbidity and mortality will be conducted using the intention-totreat approach. Logistic regression or Cox proportional hazard model will be carried out for different subgroups. We plan a prespecified subgroup analysis in: (1) patients with $\mathrm{CPB}$ duration $\geq 90 \mathrm{~min}$ and (2) patients with $\mathrm{CPB}$ duration $<90 \mathrm{~min}$. For all the statistical tests, a $\mathrm{p}$ value $<0.05$ will be considered significant. Statistical analyses will be done using statistical software SPSS V.19.0.

\section{Missing data}

Missing data for the primary outcome (baseline and peak SCr levels) will be assumed to be missing completely, and these patients will be excluded from the efficacy analysis. If data are 'missing at random' and accounting for a small proportion, we will first perform analysis by excluding missing values; if data are 'not missing at random', we will attempt to contact authors, investigators to obtain data. Nevertheless, if there is no reply, we will then perform multiple imputations to impute missing values and conduct subsequent analysis to estimate the robustness of the findings.

\section{DISCUSSION}

To our knowledge, this will be the first prospective RCT to investigate the prevention of CS-AKI with CPB for paediatric patients receiving GDP strategy aimed at maintaining $\mathrm{DO}_{2} \mathrm{i} \geq 360 \mathrm{~mL} / \mathrm{min} / \mathrm{m}^{2}$ compared with those receiving standard CPB flow rate management factored on BSA and temperature. The results of this RCT will fill the gap of GDP strategy in paediatric cardiac surgery patients, and provide new ideas for optimising the perfusion strategy and improving the prognosis in paediatrics, which has significant clinical value.

CS-AKI is defined as eCrCl $>25 \%$ of baseline within the first 7 days postsurgery. Although several standardised definitions for CS-AKI have been developed, no consensus exists regarding which to use in children. In our study, pRIFLE criteria is selected due to following reasons. First, pRIFLE is more sensitive, identifying a greater number of mild AKI cases. ${ }^{22}{ }^{23}$ The pRIFLE criteria are based on changes in eCrCl while AKIN and The Kidney Disease: Improving Global Outcomes are mainly based on changes in SCr. Many studies reported that eCrCl in infants better reflects renal function than $\mathrm{SCr}$ alone due to their insufficient renal function. ${ }^{24} 25$ Second, small children, compared with older children and adults, have very low baseline SCr owing to the dependency of SCr on muscle mass. Thus, the advantage of the 'increase in $\mathrm{SCr}>0.3 \mathrm{mg} / \mathrm{dL}$ ' criterion in the AKIN disappears with regard to children with baseline $\mathrm{Cr} \leq 0.5 \mathrm{mg} / \mathrm{dL}$.

GDP is a refined and individualised CPB perfusion strategy proposed in recent years. It involves aggressive patient management and incorporates continuous monitoring of oxygen metabolism parameters, such as $\mathrm{DO}_{2} \mathrm{i}$, carbon dioxide production and oxygen extraction index, so as to tailor perfusion to each patient's specific needs. ${ }^{26}$ Several clinical studies have shown that a GDP strategy aimed at maintaining $\mathrm{DO}_{2} \mathrm{i}$ above the critical threshold (reported to be $260 \sim 300 \mathrm{~mL} / \mathrm{min} / \mathrm{m}^{2}$ in adults) during $\mathrm{CPB}$, is associated with reduced risk of CS-AKI. ${ }^{8-10} 13$ However, no clear standards of paediatric critical $\mathrm{DO}_{2} \mathrm{i}$ exist. Our prior prospective cohort study has found that the nadir $\mathrm{DO}_{2} \mathrm{i}<353 \mathrm{~mL} / \mathrm{min} / \mathrm{m}^{2}$ was an independently risk predictor of CS-AKI in infants. We chose a conservative target of $360 \mathrm{~mL} / \mathrm{min} / \mathrm{m}^{2}$ in our RCT to remain safely above the risk threshold we found. The main intervention in this study is to tailor the perfusion flow according to the $\mathrm{HCT}$ value so as to maintain a $\mathrm{DO}_{2} \mathrm{i}$ above the prespecified threshold. In the event of low HCT values, an increasing perfusion flow was unable to maintain the $\mathrm{DO}_{2} \mathrm{i}$ above the threshold, and ultrafiltration and/or PRBC transfusion could be considered.

Our research has certain limitations. First, our study lacks patients treated under hypothermic conditions $<32^{\circ} \mathrm{C}$, when different limits of critical $\mathrm{DO}_{2} \mathrm{i}$ are likely to occur. Second, CS-AKI is certainly a multifactorial event, and we could not include all of the possible determinants in our analyses. Third, although adjusting SCr values for fluid balance will be used in our study, SCr has several limitations for diagnosing early AKI and the incidence of CS-AKI may be underestimated. Biomarkers of renal cell injury might help us identify additional patients at an earlier stage. ${ }^{27}$ 


\section{Patient and public involvement}

Patients' priorities, experience and preferences will be not involved in the development of the research question and outcome measures, the design of this study or the recruitment and conduct of the study. The results will be not disseminated to study participants.

\section{ETHICS AND DISSEMINATION}

The study has been approved by the Biomedical Research Ethics committee of West China Hospital of Sichuan University on 5 December 2019 (approval number: 2019(863)). Written informed consent will be obtained from all patients before inclusion. Trial oversight will be performed by an independent Data Safety and Monitoring Board (Biomedical Research Ethics committee). The task is to oversee the safety of the trial subjects and to monitor integrity and validity of the conduct of the clinical trial. Results will be disseminated through peerreviewed publications and conferences.

Contributors YZ helped designing the trial, collected and analysed the data and drafted the manuscript. XZ helped designing the trial, performed the study. BW collected data and analysed the data. LG performed study coordination and collected date. RZ conceived the study, designed the trial and drafted the manuscript. All authors read and approved the final manuscript.

Funding This study will be supported by 1.3.five project for disciplines of excellence - Clinical Research Incubation Project, West China Hospital, Sichuan University (approval number: 2018HXFH034), and by grants from the National Nature Science Foundation of China (approval number: 81970346).

Competing interests None declared.

Patient consent for publication Not required.

Provenance and peer review Not commissioned; externally peer reviewed.

Supplemental material This content has been supplied by the author(s). It has not been vetted by BMJ Publishing Group Limited (BMJ) and may not have been peer-reviewed. Any opinions or recommendations discussed are solely those of the author(s) and are not endorsed by BMJ. BMJ disclaims all liability and responsibility arising from any reliance placed on the content. Where the content includes any translated material, BMJ does not warrant the accuracy and reliability of the translations (including but not limited to local regulations, clinical guidelines, terminology, drug names and drug dosages), and is not responsible for any error and/or omissions arising from translation and adaptation or otherwise.

Open access This is an open access article distributed in accordance with the Creative Commons Attribution Non Commercial (CC BY-NC 4.0) license, which permits others to distribute, remix, adapt, build upon this work non-commercially, and license their derivative works on different terms, provided the original work is properly cited, appropriate credit is given, any changes made indicated, and the use is non-commercial. See: http://creativecommons.org/licenses/by-nc/4.0/.

\section{ORCID iD}

Yan Zhang http://orcid.org/0000-0003-2146-1052

\section{REFERENCES}

1 Van Driest SL, Jooste EH, Shi Y, et al. Association between early postoperative acetaminophen exposure and acute kidney injury in pediatric patients undergoing cardiac surgery. JAMA Pediatr 2018;172:655-63.

2 Yoneyama F, Okamura T, Takigiku K, et al. Novel urinary biomarkers for acute kidney injury and prediction of clinical outcomes after pediatric cardiac surgery. Pediatr Cardiol 2020;41:695-702.
3 Li S, Krawczeski CD, Zappitelli M, et al. Incidence, risk factors, and outcomes of acute kidney injury after pediatric cardiac surgery: a prospective multicenter study. Crit Care Med 2011;39:1493-9.

4 Yuan S-M. Acute kidney injury after pediatric cardiac surgery. Pediatr Neonatol 2019;60:3-11.

5 Wang Y, Bellomo R. Cardiac surgery-associated acute kidney injury: risk factors, pathophysiology and treatment. Nat Rev Nephrol 2017; 13:697-711.

$6 \mathrm{Li} \mathrm{S}$, Fu S, Xiao Y, et al. Recent perioperative pharmacological prevention of acute kidney injury after cardiac surgery: a narrative review. Am J Cardiovasc Drugs 2017;17:17-25.

7 Leow $\mathrm{EH}, \mathrm{Chan} \mathrm{YH}, \mathrm{Ng} \mathrm{YH}$, et al. Prevention of acute kidney injury in children undergoing cardiac surgery: a narrative review. World $J$ Pediatr Congenit Heart Surg 2018;9:79-90.

8 Newland RF, Baker RA. Low oxygen delivery as a predictor of acute kidney injury during cardiopulmonary bypass. J Extra Corpor Technol 2017;49:224-30.

9 Ranucci M, Romitti F, Isgrò G, et al. Oxygen delivery during cardiopulmonary bypass and acute renal failure after coronary operations. Ann Thorac Surg 2005;80:2213-20.

10 de Somer F, Mulholland JW, Bryan MR, et al. O2 delivery and CO2 production during cardiopulmonary bypass as determinants of acute kidney injury: time for a goal-directed perfusion management? Crit Care 2011;15:R192.

11 Murphy GS, Hessel EA, Groom RC. Optimal perfusion during cardiopulmonary bypass: an evidence-based approach. Anesth Analg 2009;108:1394-417.

12 Baker RA. Variation in measurement and reporting of goal directed perfusion parameters. J Extra Corpor Technol 2017;49:P2-7.

13 Ranucci M, Isgrò G, Romitti F, et al. Anaerobic metabolism during cardiopulmonary bypass: predictive value of carbon dioxide derived parameters. Ann Thorac Surg 2006;81:2189-95.

14 Ranucci M, Johnson I, Willcox T, et al. Goal-directed perfusion to reduce acute kidney injury: a randomized trial. $J$ Thorac Cardiovasc Surg 2018;156:1918-27.

15 Mukaida H, Matsushita S, Kuwaki K, et al. Time-dose response of oxygen delivery during cardiopulmonary bypass predicts acute kidney injury. J Thorac Cardiovasc Surg 2019;158:492-9.

16 Bailie GR, Uhlig K, Levey AS. Clinical practice guidelines in nephrology: evaluation, classification, and stratification of chronic kidney disease. Pharmacotherapy 2005;25:491-502.

17 Akcan-Arikan A, Zappitelli M, Loftis LL, et al. Modified rifle criteria in critically ill children with acute kidney injury. Kidney Int 2007;71:1028-35.

18 Schwartz GJ, Muñoz A, Schneider MF, et al. New equations to estimate GFR in children with CKD. J Am Soc Nephrol 2009;20:629-37.

19 Burkhardt BEU, Rücker G, Stiller B. Prophylactic milrinone for the prevention of low cardiac output syndrome and mortality in children undergoing surgery for congenital heart disease. Cochrane Database Syst Rev 2015:CD009515..

20 O'Brien SM, Clarke DR, Jacobs JP, et al. An empirically based tool for analyzing mortality associated with congenital heart surgery. $J$ Thorac Cardiovasc Surg 2009;138:1139-53.

21 Rizza A, Romagnoli S, Ricci Z. Fluid status assessment and management during the perioperative phase in pediatric cardiac surgery patients. J Cardiothorac Vasc Anesth 2016;30:1085-93.

22 Lex DJ, Tóth R, Cserép Z, et al. A comparison of the systems for the identification of postoperative acute kidney injury in pediatric cardiac patients. Ann Thorac Surg 2014;97:202-10.

23 Sutherland SM, Byrnes JJ, Kothari M, et al. AKI in hospitalized children: comparing the pRIFLE, akin, and KDIGO definitions. Clin J Am Soc Nephrol 2015;10:554-61.

24 Zappitelli M, Parikh CR, Akcan-Arikan A, et al. Ascertainment and epidemiology of acute kidney injury varies with definition interpretation. Clin J Am Soc Nephrol 2008;3:948-54.

25 Hogg RJ, Furth S, Lemley KV, et al. National kidney Foundation's kidney disease outcomes quality initiative clinical practice guidelines for chronic kidney disease in children and adolescents: evaluation, classification, and stratification. Pediatrics 2003;111:1416-21.

26 Groom RC. Is it time for goal-directed therapy in perfusion. J Extra Corpor Technol 2017;49:P8-12.

27 Yoneyama F, Okamura T, Takigiku K, et al. Novel urinary biomarkers for acute kidney injury and prediction of clinical outcomes after pediatric cardiac surgery. Pediatr Cardiol 2020;41:695-702. 